\title{
Rhétorique de la distance : comment le poète négocie sa place auprès du patron au début de l'époque abbasside
}

\author{
Rhetorics of Distance: How Poets Negotiate Their \\ Positions with Their Patrons at the Beginning of \\ the Abbasid Era
}

\author{
Mathias Hoorelbeke \\ Institut national de langues et civilisations orientales \\ Centre d'études et de recherches Moyen-Orient Méditerranée
}

Cet article aborde la relation unissant le poète abbasside à son patron non du point de vue des interactions verbales ou de la circulation des richesses, mais par l'analyse des positions spatiales des deux parties, qui contribuent elles aussi à la négociation de la distance entre le client et son protecteur. Cette proxémique s'engage dès la porte de la demeure du patron car, même si ce dernier est alors invisible, il n'est pas totalement absent et organise le filtrage des entrées, garantissant ainsi l'accès aux poètes qui acceptent les règles du jeu. Une fois en présence du patron, des règles de préséance et de bienséance encadrent le comportement de l'aspirant, et l'expression de ses prétentions. Enfin, la séparation est elle aussi fortement régulée afin d'éviter qu'elle n'ouvre une crise. Tous ces modes de contrôle des déplacements garantissent un fonctionnement efficace et, le plus souvent, apaisé, du système patronal.

Mots-clés: Proxémie; patronage; poésie abbasside; hạğib; préséance; bienséance; négociation de la distance; congé; intercessions; mal du pays.
This article investigates the relationship between the early Abbassid poet and his patron. Instead of focusing on verbal interactions or on the circulation of wealth between them, it analyses the spatial positions of both parties, which contribute too to negotiate the distance between them. This proxemics starts from the door of the patron who, even if he cannot be seen at this stage, is not totally absent and organises the entrance screening and therefore guarantees access to the poets who accept the rules of the game. Once in front of the patron, the contender's behaviour and the expression of his pretences is organised by a set of rules of precedence and propriety. Eventually, separation is also strictly regulated in order to avoid a crisis. All these various forms of control ensure the efficient and generally peaceful functioning of the patronal institution.

Key words: Proxemics; Patronage; Poets; Abbassid Caliphate; Hājib; Rules of precedence and propriety; Negotiating the distance; Departures; Intercessions; homesickness. 
Dans un ouvrage de $2011^{1}$, Jocelyn Sharlet s'efforce de décrire comment la "rhétorique raffinée » reflète l'état des relations entre poète et patron, tout en restant évasive sur ce qu'elle place derrière cette notion. Nous proposons, pour notre part, de nous inspirer de la définition donnée par Michel Meyer : « la rhétorique est la négociation de la distance entre des individus à propos d'une question donnée ${ }^{2} »$. Si l'on admet que, dans une relation de patronage, une question essentielle pour les deux parties est l'étendue des droits et des devoirs dont ils jouissent vis-à-vis de l'autre partie, on conviendra qu'une importante partie des interactions et des rapports entre le poète et son patron a pour objectif (non exclusif) de renégocier et, parfois, redéfinir l'étendue des obligations réciproques des parties. Or, l'observation des différentes modalités de ces interactions montre que cette négociation de la distance ne se joue pas seulement au niveau des interactions verbales. Par exemple, la remise cérémonielle de dons, dans un contexte où la subsistance des poètes est fréquemment assurée par des revenus périodiques déconnectés de toute performance poétique ${ }^{3}$, est l'occasion pour les deux parties d'essayer d'infléchir ou de consolider la relation. Il ne semble donc pas abusif de parler d'une rhétorique du don.

De la même manière, il nous semble possible de trouver, dans les anecdotes que le Livre des chansons ${ }^{4}$ rapporte à propos des poètes en

${ }^{1}$ Sharlet, Patronage and Poetry in the Islamic World: Social Mobility and Status in the Medieval Middle East and Central Asia.

${ }^{2}$ Meyer, Principia rhetorica : Théorie generale de l'argumentation, p. 22.

${ }^{3}$ Pour une approche statistique sommaire, voir notre article "Rhétorique du don : patronage, performance poétique et rétribution dans les premières décennies du califat abbasside".

${ }^{4}$ Nous n'ignorons ni la logique propre des habar véhiculés par les ouvrages d'adab, ni les réécritures qu'ils opèrent non seulement sur la poésie (Gruendler, "Qașīda: Its Reconstruction in Performance", pp. 325-389), mais également sur la prose elle-même (Osti, "Ibn Bassām: A Case Study on Poetry and Power"). On pourrait en outre soulever les contradictions du Livre des chansons et l'invraisemblance même de certains récits. Il nous semble néanmoins que cet ouvrage peut être exploité malgré ces objections, pour plusieurs raisons que nous indiquerons de manière extrêmement succincte ici. Tout d'abord, nous connaissons, grâce aux travaux de Hilary Kilpatrick, les méthodes de travail d'Abū l-Farağ al-Ișbahānī, qui allie aux exigences de l'adab un grand souci d'exactitude qui l'amène à évacuer les récits invraisemblables, et à exprimer clairement ses doutes quand il ne peut trancher (Kilpatrick, Making the Great Book of Songs: Compilation and the Author's Craft in Abu l-Faraj al-Ișbahānī's Kitāb al-aghān̄̄, pp. 89-127). Certes, il demeure dans cet ouvrage quelques récits invraisemblables pour le lecteur contemporain, mais 
activité dans les premières décennies de l'époque abbasside ${ }^{5}$, des marques tangibles d'une rhétorique de la distance. En d'autres termes, nous postulons que les placements et les déplacements des poètes et de leurs patrons ne relèvent pas simplement de nécessités pratiques ou d'usages totalement extérieurs aux parties et absolument neutres à l'égard de leurs préoccupations. Non seulement la proxémie ${ }^{6}$ des protagonistes reflète à la fois l'état de la relation et les prétentions des parties pour l'avenir, mais en plus, ses manifestations sont l'occasion

Michael Cooperson a montré, à propos d'autres types de textes, comment les biographes acceptent parfois des histoires douteuses mais profitables au lecteur, à condition que leur statut soit aisément inférable par un lecteur averti (Cooperson, "Probability, Plausibility and "Spiritual Communion » in Classical Arabic Biography", pp. 69-83). Quant aux versions contradictoires données d'un même événement (par exemple, la joute verbale entre Muslim b. al-Walīd et al-Ḥakam b. Qunbur : chacun des deux poète est successivement crédité d'une victoire éclatante sur son adversaire), il faut les aborder en ayant en mémoire les lignes de Michel de Certeau (L'invention du quotidien. 1/Arts de faire, pp. 41-42) : «À ces jeux correspondent les récits des parties. On se raconte la belote d'hier soir ou le petit schelem de l'autre jour. Ces histoires représentent une succession de combinaisons parmi toutes celles que rend possible l'organisation synchronique d'un espace, de règles, de donnes, etc. Ce sont les projections paradigmatiques d'un choix entre ces possibles - un choix correspondant à une effectuation (ou énonciation) particulière. (...) En rejouant des parties, en les récitant, ces histoires enregistrent simultanément des règles et des coups. » Autrement dit, si ces récits ne peuvent nous dire avec certitude qui d'Ibn al-Walīd ou d'Ibn Qunbur l'a emporté, ils peuvent nous donner à voir quelques-uns des coups qu'un poète placé dans une situation similaire pourrait tenter. Notre perspective est donc bien plus celle d'une histoire des pratiques que d'une chronologie des événements.

${ }^{5}$ Le corpus sur lequel s'appuie cet article est constitué par l'ensemble des notices du Livre des chansons portant sur des poètes actifs à un moment ou à un autre de la période 750-811.

Les références au Livre des chansons sont tirées des éditions suivantes : Abū 1-Farağ 'Alī b. al-Ḥusayn al-Iṣbahānī, Kitāb al-Ag̀̄ānī, Le Caire, Dār al-kutub, 1927-1961 (vol. I-XVI) et al-Hay'a al-mișriyya al- 'āmma li-l-ta'līf wa-l-našr , 1970-1974 (vol. XVIIXXIV). Elles sont présentées de la façon suivante : 6.227-3, où le premier chiffre indique le numéro du volume, le second la page et le troisième la ligne où commence l'isnād du récit dont est extraite la citation. Lorsque le habar est trop long, ou qu'une information doit être précisément isolée, les références sont suivies d'un astérisque (6.227-3*) : c'est alors la première ligne du passage pertinent qui est indiquée, et non l'isnād.

${ }^{6}$ Pour être complète, une étude de la rhétorique de la distance devrait également se placer au niveau macroscopique et englober la géographie des déplacements des poètes d'une région à l'autre de l'empire. Il faudrait alors faire la part entre les facteurs socioéconomiques généraux, les effets des liens personnels de walā' et le prestige poétique spécifique accumulé par certains lieux, comme Bagdad. Toutefois, le Livre des chansons, d'où nous tirons le corpus sur lequel nous appuyons cette étude, risquerait de nous induire en erreur : il se focalise principalement sur les poètes iraqiens et exclusivement sur ceux qui ont eu suffisamment de succès pour voir certains de leurs vers mis en musique dans des compositions fameuses. 
de négociations qui impliquent le poète et le patron, mais aussi les tiers, comme nous aurons l'occasion de le voir. Si ces négociations sont parfois muettes, les différents placements du poète doivent fréquemment s'accompagner d'une production poétique dont les caractères spécifiques sont déterminés par les contraintes spatiales qui pèsent sur le poète. Afin de rendre compte des différentes dimensions de ce système complexe de déplacement des corps et des mots, nous examinerons les différentes étapes de la relation : 1'attente à la porte du patron, le comportement en présence de celui-ci, puis le congé.

\section{La porte du prince}

La première difficulté à laquelle se heurte le poète engagé (ou aspirant à s'engager) dans une relation patronale, est bien sûr d'accéder au patron, d'entrer son espace, et donc de franchir sa porte ${ }^{7}$. Il pourrait sembler paradoxal de parler de négociation de la distance à ce stade : le maître des lieux est invisible et la relation semble de fait être en suspens. Néanmoins, la porte où attendent les solliciteurs peut rapidement devenir un lieu de manifestation publique de son statut social ; il ne peut donc se désintéresser de ce qui s'y passe. En outre, la discrète présence patronale se traduit par les règles d'accès à son espace privé que le maître des lieux édicte. Ainsi, lorsque le poète cherche à franchir la porte dans le cadre d'une audience publique, qu'il sollicite une comparution individuelle ou qu'il fasse appel à un intercesseur, il doit composer avec ces règles et choisir de s'y soumettre ou biaiser et les contourner.

\section{La manifestation du statut du patron dans l'espace public}

La porte remplit une double fonction : en même temps qu'elle clôt un espace privé, elle est un lieu où le statut du patron se manifeste dans l'espace public. En effet, même lorsqu'elles sont le lieu de résidence d'un personnage investi de fonctions publiques, les demeures des

\footnotetext{
${ }^{7}$ Voir, pour des exemples tirés d'autres sources et portant sur une période légèrement postérieure, l'article de Gruendler, "Meeting the Patron: an Akhbār Type and Its Implications for Muhdath Poetry”, pp. 62-68.
} 
dignitaires et des princes relèvent du domaine privé. Comme le note Matthieu Tillier ${ }^{8}$ à propos des cadis d'Iraq à l'époque abbasside, en dépit des injonctions très claires des ouvrages juridiques qui rappellent sans cesse que le juge doit être accessible à tous, il n'est pas rare que ceux-ci organisent les audiences à leur domicile et que les plaignants se trouvent contraints d'attendre dans la rue que la porte s'ouvre. À ce titre, les maisons des princes et des califes où l'accès se fait par une demande d'audience (isti' $\underline{\text { dān}}$ ) ne se distinguent guère des demeures plus modestes. Cette porte close, qui n'est que la manifestation concrète de la fermeture de l'espace privé, peut aussi devenir une marque ostensible du statut social du maître de maison, ce que ne manquent pas d'exploiter les poètes. Un jour qu'Ašğa' al-Sulamī (m. 208/824) voit une foule massée devant la porte de Muhammad b. Manșūr, il lui adresse le distique suivant :

À la porte d'Ibn Manșūr / des signes de prodigalité se manifestent

Par groupes ; une porte suffit à signifier la noblesse / quand on y voit les gens s'y masser.

Le destinataire déclare ces vers les plus beaux qui lui aient été dédiés (18.224-4). Mais cette fonction ostentatoire de la porte peut être utilisée par le poète pour faire pression sur le patron. Ainsi, Baššār $b$. Burd (m. 167/783) fait-il écrire des vers d'istinğ $\bar{a} z$ sur la porte de 'Uqba b. Salm (m. 167/783), c'est-à-dire en un lieu où non seulement le patron, mais aussi les visiteurs qui attendent à la porte pourront en prendre connaissance (3.182-1). Toutefois, la porte ne saurait rester perpétuellement fermée sans devenir le symbole de l'avarice du patron. Aussi, quand Muslim b. al-Walīd (m. 208/823) satirise le général Huzayma b. Hāaim (m. 213/819), il ne manque pas d'évoquer sa porte de fer, symbole de son avarice (19.49-12*). La porte du patron doit donc s'ouvrir, mais de façon réglée et souvent visible.

\section{Audiences collectives}

Ces règles, fixées par le patron, laissent au poète des marges de manœuvre plus ou moins grandes. Dans le cas des audiences

\footnotetext{
${ }^{8}$ Tillier, "Un espace judiciaire entre public et privé. Audiences de cadis à l'époque 'abbāside".
}

Al-Qantara XXXVII 1, 2016, pp. 7-37 ISSN 0211-3589 doi: 10.3989/alqantara.2016.001 
collectives, que nous examinerons en premier lieu, certaines contraintes s'imposent de façon impérieuse - le patron fixe par exemple le moment de la comparution - et d'autres de manière plus implicite, laissant ainsi aux poètes habiles un espace de négociation.

Les audiences générales, où sont admis indifféremment les poètes et les autres visiteurs, sont autant d'occasions pour le patron de réaffirmer les liens qui l'unissent à sa clientèle. Leur moment et leur déroulement sont en général nettement encadrés. Le Livre des chansons nous montre ainsi des poètes admis auprès d'un prince lors des fêtes religieuses (18.247, 20.53 par ex.) ou du nouvel an iranien (19.282$\left.8^{*}\right)$. Les audiences collectives ont également lieu à l'occasion des grandes étapes de la vie du patron. Les événements heureux, comme les naissances ou l'accès à un poste prestigieux, les victoires et les faits mémorables, doivent faire l'objet de félicitations de la part des clients, en vers ou en prose. C'est d'ailleurs en voyant les gens féliciter al-Faḍl b. Yahyā̄ (m. 193/808) que le poète Abū 1-Naḍīr comprend que ce dernier vient d'avoir un enfant et qu'il convient donc de trousser quelques vers pour l'occasion (11.285-13). Les cérémonies de prestation d'allégeance $\left(b a y^{\prime} a\right)^{9}$ rassemblent poètes, orateurs et notables (13.287-1). Les départs ou les retours de voyage sont également l'occasion d'audiences publiques. Ainsi, nous dit-on à propos d'al-Faḍll b. Yahyyā, informé qu'il allait partir en mission :

Alors $(f a-)$, il reçut les poètes ; ils le louèrent et il les recompensa ; il examina les requêtes de ses visiteurs et les exauça. Puis tous se retirèrent (19.58-17).

Ces requêtes émanent apparemment des clients du ministre qui souhaitent être entendus avant son départ.

Les maladies peuvent également donner lieu à des audiences : soit le notable se rétablit et il convient de le féliciter, soit il meurt et il conviendra de consoler ses proches ${ }^{10}$. La raison de la réaffirmation du

\footnotetext{
${ }^{9}$ Analysées par Marsham, Rituals of Islamic Monarchy: Accession and Succession in the First Muslim Empire. L'ouvrage contient néanmoins peu d'informations sur l'usage de la poésie à l'époque qui nous intéresse.

${ }^{10}$ Exemples de poésie de voyage : poème d'Ishāa al-Mawșilī (m. 235/850) à alMu'tașim (m. 227/842) pour son retour d'une expédition militaire (5.303-12), félicitations d'Ibn Abī Ḥafșa à Ma'n b. Zā'ida alors qu'il rentre du Yémen (10.91-1). Pour un thème voisin de celui de la maladie, mais non représenté dans notre corpus, voir Bray, "Third and Fourth Century Bleeding Poetry", p. 75-92.
} 
lien en ces circonstances n'est pas difficile à comprendre : il s'agit soit de fêtes cycliques où est réaffirmé l'ordre cosmique ${ }^{11}$, soit d'événements à l'occasion desquels la fortune du patron change favorablement ou défavorablement et où, face à ces changements, la pérennité du lien doit être manifestée.

Outre ces occasions solennelles, où les poètes jouent une place de choix dans la mise en scène des vertus patronales, des audiences sont accordées collectivement aux poètes, parfois à intervalles réguliers. AlMahdī (m. 169/785) accorde ainsi une audience annuelle aux poètes, pratique qui semble avoir été suivie par d'autres califes à cette période (10.87-11*). Des audiences peuvent également être accordées quand un grand nombre de poètes attend à la porte, comme le fait al-Rašīd (m. 193/809) (4.42-12). Les ministres, comme al-Faḍl b. Yahyyā, accordent des audiences réservées aux poètes (20.340-16).

Qu'il s'agisse d'audiences générales ou d'audiences réservées aux poètes, ces circonstances ne sont guère favorables à ces derniers. Noyés dans la masse de leurs concurrents, il leur est difficile de se faire entendre, sans parler de se distinguer. Toutefois, il est possible au poète habile de tirer son épingle du jeu. Le poète Ašğa al-Sulamī est ainsi introduit devant al-Rašīd un vendredi matin avec un groupe de poètes. Comme il est le plus jeune, il récitera en dernier. La matinée avance et, quand le jeune Ašğa ' est enfin autorisé à réciter, la prière du midi est proche : il décide donc d'amputer le poème qu'il avait préparé de son traditionnel prélude amoureux et de passer directement au panégyrique (18.212-15). Encore cette audience est-elle relativement restreinte, puisque les poètes ne sont que huit et ont été convoqués la veille. La situation est encore moins favorable lorsque l'audience est totalement ouverte et que les poètes sont si nombreux qu'ils viennent à bout de la patience des laudataires. Dans ces conditions, mieux vaut pour le poète compter sur d'autres moyens que son seul talent poétique pour se distinguer : lorsqu'al-Mahdī, encore héritier du trône, est rejoint en déplacement par son fils al-Hādī (m. 170/786), poètes et orateurs se pressent pour présenter leurs félicitations. Devinant l'ennui d'al-Mahdī, Muțī' b. Iyās (m. 169/785) se contente, plutôt que d'une longue qașìda solennelle, d'un tercet d'une grande platitude. L'héritier du trône

\footnotetext{
${ }^{11}$ Stetkevych, The Poetics of Islamic Legitimacy: Myth, Gender, and Ceremony in the Classical Arabic Ode, p. 229.
} 
déclare que c'est tout ce dont il a besoin et congédie l'assemblée, non sans avoir récompensé Muțị ${ }^{`} \mathrm{~b}$. Iyās, dont la stratégie de distinction a été fructueuse (13.326-12). Ce choix de la brièveté en de semblables circonstances n'est pas isolé. Sa'īd b. Wahb (m. 209/824) en use de la même manière avec al-Faḍl b. Yahyyā, avec le même succès (20.34016). Ces quelques exemples montrent concrètement comment les circonstances de la profération affectent le texte, et comment le franchissement de la porte, à l'instar du raḥil antéislamique, laisse sa marque discrète sur la production poétique. Mais c'est bien d'une négociation qu'il s'agit, car le poète habile est ici celui qui sait sacrifier un peu de son art pour s'adapter à un dispositif qui est étranger aux préoccupations poétiques. En acceptant de s'y plier, il admet implicitement sa position subordonnée et montre qu'il connaît les règles asymétriques du jeu patronal ou, pour dire les choses plus crûment, qu'il saura rester à sa place.

Ces anecdotes suggèrent encore autre chose : lorsqu'un poète est introduit avec des concurrents, son objectif est d'être distingué de la masse de ses rivaux, distinction qui peut prendre, entre autres, la forme d'une récompense exclusive ${ }^{12}$, ou celle d'une levée de l'audience à la suite de ses vers ${ }^{13}$, ou peut encore se manifester par la permission de rester seul avec le patron après le départ de ses rivaux. Ainsi, Muslim b. al-Walīd est-il invité par al-Faḍl b. Yahyaā, après un panégyrique particulièrement réussi, à s'asseoir et à boire avec lui (19.58-17). Ce faisant, le poète passe de la masse indistincte au cercle restreint des intimes. Ce désir du poète de surpasser ses rivaux et d'être distingué personnellement, exclusivement, de refermer la porte du palais au nez de tous les autres, nous est manifesté par Marwān b. Abī Hafșa (m. ca. 182/797) lorsque Ma'n b. Zā’ida (m. 152/769) rentre du Yémen. Sa salle d'audience est alors noire de monde. Marwān, avant de réciter, empoigne les battants de la porte, comme pour affirmer la fermeture inéluctable de celle-ci après que sa poésie aura été entendue (10.91-1). Ces anecdotes montrent encore une chose : la négociation de la distance dans le cadre de la relation ne se réduit pas à un tête-à-tête entre le poète et le patron. De ce fait, la concurrence à laquelle est soumis le poète, toujours susceptible de se voir préférer un rival, le force à

${ }^{12}$ Abū 1-'Atāhiyya (m. ca. 213/828) pour des vers adressés à al-Rašīd (4.42-12).

${ }^{13} \mathrm{Sa}^{‘} \overline{1}^{\mathrm{d}} \mathrm{b}$ b. Wahb avec al-Faḍl b. Yaḥyā (20.340-16). 
prendre en compte l'attitude des autres visiteurs ${ }^{14}$. Ainsi, les disputes qui éclatent entre les visiteurs qui attendent à la porte ne sont pas extérieures à la négociation du lien patronal : qu'il s'agisse de la querelle qui oppose à la porte de 'Uqba b. Salm un jeune Hachémite à al-Sayyid al-Himyarī (m. entre 171/787 et 179/795) au sujet des mérites comparés des premiers califes (7.266-3) ou de la joute poétique qui a lieu à la porte d'al-Walīd b. Yazīd (m. 126/744) entre Ibn Mayyāda (m. 136/754 ou 149/766) et les Yéménites sur les mérites respectifs des Arabes du Nord et ceux du Sud (2.309-1), ces affrontements sont l'occasion pour les poètes de se faire remarquer et, peut-être, de gagner le droit d'entrer : même en l'absence physique du patron, le climat de concurrence constitutif de la relation de patronage poétique est à l'œuvre.

\section{Comparutions individuelles}

En dehors de ces audiences publiques ou semi-publiques, le seul moyen pour le poète d'être admis à franchir la porte est d'obtenir une autorisation personnelle. Nous avons eu l'occasion d'évoquer la wifäda ${ }^{15}$, qui est une autorisation de se présenter périodiquement devant le patron pour lui réciter de la poésie. Ainsi, l'accès est garanti au poète et le patron est assuré de n'être pas sollicité de façon intempestive. À ce titre, la wifäda constitue un moyen caractéristique de régulation et de négociation de la distance entre les deux parties. Mais, en l'absence de wifäda — qui implique d'ailleurs une rencontre préalable — le droit d'entrée doit être conquis : le succès n'est jamais garanti, mais cette situation, moins figée que les audiences solennelles, offre au poète des moyens plus variés de négocier la distance qui le sépare du patron. Les rapports avec l'huissier en offrent une bonne illustration ${ }^{16}$.

${ }^{14}$ Ce qui confirme l'observation de Jocelyn Sharlet, qui affirme que la compétition entre les clients, loin de perturber le patronage, le définit : Patronage and Poetry, p. 24. Le Kitāb al-Tã̆g souligne d'ailleurs cette dimension concurrentielle : le souverain doit assigner à ses commensaux des classes et des rangs, élever les uns et abaisser les autres : [Pseudo-] al-Ğāhiz, Al-Tāğ fì ahlāq al-mulūk, p. 19.

${ }^{15}$ Hoorelbeke, "Rhétorique du don".

${ }^{16}$ Sur la question de la réception du poète et le filtrage exercé à l'entrée, voir d'autres illustrations chez Sharlet, Patronage and Poetry, pp. 25-28. 
Le rôle de l'huissier ${ }^{17}$ peut d'abord se limiter, en l'absence de dispositions contraires du maitre des lieux, à transmettre au patron des billets de la part du poète. Ces billets sont souvent en vers et, là encore, la forme de la poésie qui s'y exprime est très contrainte, à la fois par le support et les circonstances de l'énonciation. Le poète doit y montrer en peu de mots qu'il vaut la peine d'être entendu, ce qui demande un certain sens de la formule et de la concision. La plupart des billets transmis revêtent la forme de vers d'excuses qui, à la différence des poèmes d'excuse de la grande tradition poétique, se caractérisent par leur brièveté. C'est ainsi, par exemple, que procède Husayn b. alḌaḥhāk (m. 250/854) lorsque le calife al-Mu'tașim lui ferme sa porte plusieurs jours de suite, à la suite d'une dispute (7.167-7). Mais, plus rarement, le patron peut ordonner au hăğgib de ne pas lui faire parvenir les billets d'un personnage importun (5.325-3*). Al-Faḍl b. al-Rabī' (m. 208/823) refuse ainsi de recevoir les billets d'Isḥāq al-Mawșilī à la suite d'une fâcherie. La fermeture est alors totale, et le poète doit déployer une grande ingéniosité pour parvenir à ses fins.

Le poète va devoir alors prendre en compte la marge variable de pouvoir discrétionnaire ${ }^{18}$ de $1^{\prime}$ huissier et tenter de le circonvenir. Là encore, ces manœuvres font fréquemment appel à une production poétique, satirique ou élogieuse. Souvent, ces vers recourent à l'implicite et au sous-entendu, le poète à la merci du bon vouloir de l'huissier ne pouvant se permettre ni d'exiger ni de s'humilier trop franchement devant un personnage subalterne. Ainsi, à un huissier qui lui demandait de prendre patience, Baššăr rétorque qu'on ne prend patience que face aux malheurs. Le hăăgib comprend la menace implicite

${ }^{17}$ Le mot employé en arabe est celui de hăğğib, qui désigne toute personne chargée de filtrer les entrées dans une demeure et ne doit donc pas être trop vite assimilé à la fonction de chambellan, développée par Dominique Sourdel dans son article Hāajjib de l'Encyclopédie de l'Islam. Les deux acceptions du terme peuvent d'ailleurs cohabiter dans un même habar (13.151-3).

${ }^{18}$ Ce pouvoir se fait de plus en plus impérieux au palais califal avec l'institutionnalisation du cérémonial abbasside, au $\mathrm{IV}^{\mathrm{e}} / \mathrm{X}^{\mathrm{e}} \mathrm{s}$. Voir à ce sujet El-Cheikh, "The Institutionalisation of Abbāsid Ceremonial". L'éloignement symbolique et physique du calife donne aux personnages qui peuvent accéder à la fois aux espaces publics et à ceux de l'intimité l'occasion d'asseoir une influence sans commune mesure avec celle des hăăgib du VIII' siècle que nous décrivons ici. C'est en particulier le cas des eunuques et des intendantes du harem califal. Voir, du même auteur, "Servants at the Gate: Eunuchs at the Court of al-Muqtadir" et "The Qahramâna in the Abbasid Court: Position and Functions", pp. 41-55. 
et préfère laisser passer le poète plutôt que de s'exposer à la satire (3.167-6). Plusieurs habar mettent en scène le poète-chanteur Ishāq alMawșilī et le hặğib d'al-Faḍl b. al-Rabī', nommé 'Awn. À la suite d'une dispute avec son patron, Isḥāq se voit interdire l'entrée. Dans l'une des versions de cette dispute, il satirise 'Awn par des vers l'accusant d'être sodomite passif puis essaie d'obtenir son aide en lui adressant un distique où il remarque que son nom, 'Awn, devrait l'inciter à accorder son aide et lui promet une monture ou un jeune esclave « qui le satisfera » s'il le fait parvenir jusqu'à al-Faḍl (5.346-17). Dans une autre version (5.324-15), seuls ces vers de promesse sont proférés. Dans tous les cas, la stratégie s'avère efficace puisque le poète parvient à ses fins.

Ces sous-entendus ne sont d'ailleurs pas nécessairement destinés à l'huissier lui-même. Dans l'une des versions de cette anecdote, le portier décide d'apporter une aide active au poète en disgrâce, va montrer le distique à al-Faḍl et lui laisse entendre qu'il aimerait bien obtenir la récompense promise. 'Awn est visiblement un esclave peu au fait des subtilités et des sous-entendus de la poésie. Il ne s'avise pas que les vers élogieux qui lui sont adressés et qui lui promettent un jeune esclave en récompense ne sont qu'une autre manière de souligner son goût pour les garçons. Son maître, au contraire, perçoit immédiatement le sous-entendu et en avertit le portier, qui n'y prête pas attention. Ainsi, la stratégie déployée par Ishāāq est particulièrement subtile : répugnant sans doute à faire l'éloge d'un esclave, il produit des vers dont l'ambiguïté ne peut être saisie que par le connaisseur qu'est al-Faḍl. Ce faisant, il crée avec lui une connivence qui, malgré la distance spatiale, atteste d'une proximité intellectuelle et sociale indéniable, qui vainc les résistances du vizir. La réconciliation se fait aux dépens de l'huissier. Ce cas n'est à vrai dire pas isolé.

Parce que les huissiers sont pourvus d'une certaine autonomie, parce qu'ils ne peuvent que rarement se cantonner à la neutralité du rôle de porte-parole de leur maître, ils constituent un outil essentiel d'ambiguation des rapports entre le patron et son protégé. Dans le cadre de la négociation permanente du lien entre patron et client, le hăğgib est une variable d'ajustement sur qui on pourra toujours faire porter la faute si jamais la relation s'interrompt. La chose nous est crûment manifestée par une anecdote où Faḍll b. Yahyā exprime à Ibrāhīm alMawșilī (m. 188/804) son déplaisir de voir que son fils Isḥāq ne lui rend plus visite. C'est Isḥāq qui raconte : 
— Comment se fait-il que je ne voie plus Isḥāq ? demanda al-Faḍl b. Yahyaà à mon père. Dis-moi ce qu'il devient.

- Il va bien, répondit-il.

Cette réponse éveilla les soupçons d'al-Faḍl :

— Est-il malade?

- Non, mais il est venu vous voir plusieurs fois, et votre serviteur Nāfị lui a interdit l'entrée. Il s'en est froissé.

— S'il lui interdit encore d'entrer, qu'il le baise ! s'exclama [al-Faḍl].

Mon père vint me trouver et me dit: «Va le voir. Il s'est enquis de toi. » Et il me raconta ce qui s'était passé. Je me rendis [au domicile d'al-Faḍl] et l'accès me fut à nouveau interdit. Quand al-Faḍl sortit pour quelque course, je me précipitai vers lui pour lui remettre un billet sur lequel j'avais écrit :

Puissé-je me sacrifier pour vous sauver de tous les maux! C'est à votre bon jugement que je confie ma plainte contre certains

Qui m'empêchent de venir saluer, ce que je ne peux faire qu'en cachette.

J'ai suivi votre injonction concernant Nāfid, et cela ne l'a rendu que plus rétif.

Quand il le lut, il se mit à rire jusqu'à n'en plus pouvoir :

— Est-ce que tu l'as vraiment fait, vaurien?

— Non, seigneur, lui répondis-je. Je ne faisais que plaisanter.

Nāfíd en conçut une honte extrême et ne chercha plus à me nuire par la suite (5.404-8 ; variante avec Ğa'far b. Yahyāa [m. 187/803] : 5.327-8).

Là encore, les vers créent une connivence qui permet au patron et au poète de se réconcilier sur le dos du portier, à qui on fait porter la responsabilité de l'interruption de la relation. De façon semblable, quand Ḥammād 'Ağrad (m. entre 155/772 et 168/784) quitte Abū Ḩālid al-Aḥwal, il ne manque pas de souligner dans la poésie qu'il lui fait parvenir qu'il a été empêché de faire personnellement ses adieux par le portier (14.356-10).

Ainsi, le franchissement de la porte du patron s'inscrit pleinement dans la négociation du lien entre patron et poète. En outre, la concurrence et les fortes contraintes qui pèsent sur les poètes lorsqu'ils essaient de parvenir au patron génèrent une poésie où la brièveté est reine, et où l'écrit doit fréquemment se substituer à l'oral. Cette place gagnée par l'écrit à la porte des patrons nous montre qu'une attitude comme celle de Dū l-Rumma (m. ca. 117/735) ${ }^{19}$, qui voulait cacher en son temps qu'il savait écrire, serait désormais incompréhensible. Brièveté et mise par écrit : certaines caractéristiques de la poésie des secrétaires qui commencera à fleurir dans le courant du $\mathrm{IX}^{\mathrm{e}}$ siècle sont

${ }^{19}$ Marzubānī (al-), Al-Muwaššah fì ma 'āhnid al- 'ulamā' 'alā l-šu 'arā', p. 211. 
déjà présentes, et un nouveau style s'ébauche, aiguillonné par l'acceptation de l'écriture par les poètes et les contraintes engendrées par la nécessité de franchir la porte du patron.

\section{Intercessions}

Si le poète échoue à franchir la porte par ses propres moyens, il lui faut trouver un intercesseur qui ait ses entrées chez le maître de maison. La recherche de tels alliés est un des aspects de la riche vie sociale qui se développe à la porte des patrons. Comme nous allons le voir, ces intercessions influent là encore sur la parole poétique, qu'elles génèrent des poèmes indépendants ou qu'elles aboutissent à modifier l'énonciation ou la composition des vers destinés au maître des lieux.

Certains dignitaires de haut rang disposent du crédit nécessaire pour permettre à un poète d'être introduit auprès du maître des lieux et favoriser les fortunes des poètes. Comme il est statutairement impossible pour le poète de marquer sa reconnaissance en rémunérant son sponsor ${ }^{20}$, sa gratitude s'exprime par des vers de remerciement : à nouveau, le franchissement de la porte génère une poésie soumise à des contraintes originales. Ainsi, quand Abān al-Lāhịiqī (m. 200/815) quitte Bașra pour entrer en contact avec les Barmakides, il reste longtemps à la porte d'al-Faḍl b. Yahyā sans parvenir à entrer. Il adresse donc à un compagnon hachémite du ministre un poème de supplication lui demandant d'intercéder en sa faveur. Celui-ci accepte de transmettre les vers. Abān lui remet un poème dans lequel il vante ses qualités poétiques et se présente comme un investissement profitable (kanzun min kunūzi l-amīr $\underline{d} \bar{u}$ arbāh $\bar{\imath}$ ). Al-Faḍl le fait appeler et il devient rapidement un de ses intimes (23.160-1). On note que le poème adressé à l'intercesseur est sur le même mètre et la même rime que celui adressé au ministre, comme pour l'associer par avance à l'éloge du vizir et lui en donner sa part. Mais introduire un poète de talent auprès de son supérieur constitue parfois une obligation statutaire pour un patron de rang intermédiaire, et non un choix discrétionnaire. Ainsi, al-Faḍl b. al-Rabī', toujours heureux de nuire à ses vieux ennemis, présente Ašğa ${ }^{6}$

\footnotetext{
${ }^{20}$ Pour une analyse de plusieurs utilisations du don pour signifier la supériorité sociale du donateur sur le donataire, voir Sharlet, "Tokens of Resentment: Medieval Arabic Narratives about Gift Exchange and Social Conflict", pp. 72-9.
} 
al-Sulamī à al-Rašīd en disant que les Barmakides ont souhaité le garder dans une relation exclusive avec eux, au détriment du calife : «Qad iqtața'athu 'anka al-Barāmika» (18.232-14) ${ }^{21}$.

Les poètes déjà introduits peuvent, eux aussi, tirer de leur position pour favoriser l'un de leurs confrères. En voici un exemple :

Le fils d'Isḥāq m'a rapporté, d'après son père, le récit suivant : «Comme je me trouvais à la porte d'al-Fạ̣l b. Yahyyā, al-Taymī [m. 209/824], le poète, m'apporta un poème écrit sur un papier, et me demanda de le faire parvenir à al-Faḍll. Je l'examinai puis déchirai la feuille. Abū Muhammad [al-Taymī] explosa :

- Ne te suffit-il pas de dédaigner ma demande ? Tu me prives encore de la possibilité de la confier à quelqu'un d'autre !

- Je te serai plus utile que ce papier, répondis-je.

J'entrai ensuite et me rendis auprès de Yahyyā. Au cours de notre conversation, je lui dis : "J'ai avec moi un présent, et celui qui te l'envoie est à la porte." Je lui récitai ensuite le poème.

— Comment l'as-tu mémorisé ? me demanda al-Faḍl.

— Il me l'a montré tout à l'heure à la porte, et je l'ai retenu.

— Laissons cela, maintenant.

— Faites-le paraître, insistai-je.

On l'introduisit, et al-Faḍl s'enquit de l'histoire. Il la lui raconta. "Récite-moi un peu de ta poésie", demanda-t-il. Le poète s'exécuta, et je me mis à répéter ses vers et à les accompagner de commentaires flatteurs. Al-Taymī se retira ensuite.

- Répondez favorablement à la sollicitation de cet homme, demandai-je à al-Faḍl.

- Puisque tu lui accordes tant d'intérêt, je lui ferai donner 5000 dirhams.

- Puisque vous accordez un montant réduit, faites qu'il soit payé rapidement.

La somme fut apportée.

- Ma peine n'a-t-elle pas un prix ? demandai-je.

- Si, répondit al-Faḍl.

- Donnez-le-moi donc.

— Tu n'obtiendras pas autant pour ta peine que ce que j'ai accordé au poète pour son éloge.

- Accordez-moi ce qui vous plaira.

Il me fit remettre 3000 dirhams, que j'ajoutai aux 5000 autres et que je fis envoyer [à al-Taymī.] » (20.51-8).

Ici, la soumission au jeu patronal ne s'inscrit donc pas dans le texte poétique lui-même, mais dans son énonciation : Isḥāq récite le poème en entier, et prive de ce fait son auteur, al-Taymī, de la possibilité de le faire lui-même. Le poète est dépossédé de son panégyrique, même s'il en touche le prix. En effet, contrairement à d'autres intercesseurs, Isḥāq

${ }^{21}$ On trouve plusieurs illustrations du principe selon lequel « it is harām for the servant to keep what is suitable for the master (instead of giving it to him) », mettant en scène les Barmakides, dans l'article de Sharlet susmentionné, “Tokens of Resentment”, pp. 84-88. 
se fait rémunérer par le patron. Ces intercessions de poètes au profit de leurs confrères ne sont pas toujours guidées par l'esprit de lucre. Des liens de patronage, comme ceux qui unissent un poète à son rāwiya, peuvent également justifier ce genre d'aide : ainsi al-'Attābī (m. 208/823) fait-il entrer son élève Manșūr al-Namarī (m. av. 193/809) auprès du même al-Faḍl b. Yahyyā. Le ministre lui ouvrira ensuite les portes de Hārūn al-Rašīd (13.140-13*).

D'autres intercesseurs ne se contentent pas d'exercer leur influence au profit des outsiders : ils les aident en outre à reformuler leur production en des termes plus adaptés aux contraintes de la situation. C'est ainsi qu'en use Muhammad al-Baydaq ${ }^{22}$. Ce personnage, qualifié de rāwiya, est attaché à des hautes personnalités, dont le calife al-Rašīd. Il récite la poésie avec un tel talent qu'il peut amener ses auditeurs à l'extase (tarab), comme les chanteurs. Il est spécialisé dans la poésie des Modernes, autre point qui l'écarte des collecteurs de poésie (13.146-15;20.47-3). Muslim b. al-Walīd rencontre al-Baydaq à la porte de Yazīd b. Mazyad (m. 175/801). Le poète désespère alors d'approcher le général. Al-Baydaq demande à Muslim de lui réciter une partie du panégyrique qu'il destine à Yazīd, puis en extrait deux vers, lui en demande quelques autres et va les présenter à Ibn Mazyad. Il négocie ensuite la récompense du poète (19.39-16). Cet excellent intermédiaire, qui narre ce récit à la première personne, ne nous dit pas pourquoi il vient en aide à ce jeune poète encore inconnu. La réponse nous est donnée dans la notice consacrée à Manșūr al-Namarī. AlBaydaq récite des vers de ce poète à al-Rašīd. D'extase, le calife renverse la table sur laquelle il mangeait et fait envoyer au poète la somme de 7000 dinars. Mais ce dernier refuse de reverser au rāwiya le moindre sou. Al-Baydaq, dont les services ne sont donc pas désintéressés, se venge de l'ingratitude d'al-Namarī en récitant au calife des vers du même poète dans lesquels il pleure les Gens de la maison du Prophète. Furieux d'entendre ces vers pro-alides, le calife ordonne que leur auteur soit mis à mort (13.146-15). Muhammad al-Baydaq a donc l'oreille des princes. Par sa connaissance des goûts des patrons et des usages de la poésie de cour, il peut être un allié précieux ou un adversaire redoutable. Le Livre des chansons nous apprend par ailleurs

\footnotetext{
${ }^{22}$ L'épisode qui suit est analysé, avec d'autres exemples de reformulation de la poésie, par Gruendler dans son article "Qașīda: Its Reconstruction in Performance", pp. 349-50. Le habar en question est traduit en anglais p. 380-382.
} 
qu'al-Ma'mūn (m. 218/833) avait lui aussi un rāwiya nommé Abū 1Hasan (19.108-14).

L'adaptation des vers d'un poète peut également se faire dans le cadre d'une chanson. On dispose de plusieurs exemples de poètes appelés par des califes après que ces derniers ont entendu leurs vers chantés. Les chanteurs peuvent ainsi favoriser les carrières : un chant de Hakam al-Wādī (m. v. 180/796) attire ainsi l'attention du calife alWalīd b. Yazīd sur des vers Muțī‘ b. Iyās. Interrogé, le chanteur décrit l'auteur des vers comme « un de vos esclaves, commandeur des croyants, que j'agréerais pour vous servir » ('abd laka yā amīr almu'minīn ardăhu li-hidmatika). La recommandation est on ne peut plus claire (13.277-13). À en croire Abū 1-Farağ al-Ișbahānī, plusieurs poètes ont vu leur carrière favorisée par des chanteurs : ainsi, Ibn Sayāba (m. 198/814) est-il décrit comme un poète dont la production est sans grand intérêt, mais qui était ami avec la famille Mawșilī. Ces derniers mettaient ses vers en musique et le recommandaient au calife et aux vizirs, et recevaient de lui des louanges en vers $\left(12.88-3^{*}\right)$. De même, Abū l-Asad (m. ap. 188/804), poète à la production médiocre (mutawassit al-ši $r$ ), bénéficie-t-il de son amitié avec le chanteur 'Allawayh (m. 235/850) qui met en musique beaucoup de ses vers et les fait connaître aux grands (yașiluhu bi-l-akābir). Ainsi, la médiation des chanteurs, qui permettent aux poètes de franchir la porte des patrons, donne lieu à une production poétique particulière. Il peut s'agir d'éloges adressés par le poète en remerciement pour le service qui lui a été rendu, comme le fait Ibn Sayāba avec les Mawșilī. Mais si les chanteurs mettent en avant des poètes jugés par ailleurs médiocres, c'est sans doute que leur production répond mieux que d'autres aux critères ou aux contraintes qui pèsent sur les musiciens-chanteurs dans l'exercice de leur art. Cette adaptation par certains poètes de leur production aux attentes des chanteurs est-elle consciente et recherchée ? Notre corpus ne permet pas de trancher cette question ${ }^{23}$.

\footnotetext{
${ }^{23}$ Sur cette question se reportera à l'article de Bencheikh, "Les musiciens et la poésie. Les écoles d'Isḥāq al-Mawșilī (m. 225 H.) et d'Ibrāhīm Ibn al-Mahdī (m. 224 H.)". La plupart des données qu'il exploite sont tirées du Livre des chansons et sa thèse peut se résumer ainsi : « Mais, disons-le tout de suite, aucun des arguments avancés pour prouver l'influence de l'art musical sur la création poétique n'est convaincant, et les hypothèses avancées se basent, la plupart du temps, sur des impressions ou sur des investigations fragmentaires. Nous croirions plutôt, au vu de la nature des relations qui lient le poète et
} 
Le chanteur, en se portant garant et en adaptant les vers du poète constitue en tout cas un intercesseur de choix.

La porte du patron est un lieu central pour saisir la logique de la circulation des poètes et appréhender la manière dont on gagne l'accès au maître des lieux. Le patron, s'il y est invisible, n'en est jamais totalement absent. Il donne des audiences, reçoit des billets et des demandes d'intercession. Le poète, quant à lui, doit constamment ajuster ses prétentions et ses aspirations aux exigences du système patronal : la concurrence des poètes, le recours à des intercesseurs, l'ordre des comparutions imposent des choix aux poètes. Ils peuvent refuser de se plier aux exigences du système patronal, de compromettre leur art et leur dignité pour gagner la faveur d'un patron, mais risquent de se trouver mis à l'écart. À l'inverse, ceux qui acceptent de se soumettre à ces contraintes montrent qu'ils ont intériorisé les règles du jeu patronal et que, s'ils sont introduits, ils sauront tenir leur place. À cet égard, la porte du patron fonctionne comme un lieu de filtrage efficace.

\section{La compagnie du prince}

Une fois le poète admis auprès du maître des lieux, la négociation de la distance se fait plus directe mais, là encore, elle ne se réduit pas à un tête-à-tête : le respect des règles de préséance et de bienséance, qui encadrent l'expression des revendications des poète, est assuré autant par l'assistance et les concurrents que par le patron lui-même.

\section{Préséances}

Tenter de choisir les modalités de sa prise de parole est une manière de revendiquer implicitement un statut dans une assemblée. Mais, en la matière, tous les coups ne sont pas permis. Des règles de préséance organisent la circulation des visiteurs mais aussi leur proximité vis-à-

le compositeur, à un développement parallèle des deux arts. S'il se crée un type de mélodie qui convient à un certain type de poésie - nous pensons ici à la production élégiaque c'est que le milieu bagdadien agit simultanément sur le muġann̄̄ et sur le poète qui finissent par puiser à une inspiration commune. » À vrai dire, le problème reste entier, puisqu'il faudrait déterminer comment le milieu bagdadien agit sur ces deux acteurs et quels sont les facteurs qui permettent l'émergence de cette inspiration commune. 
vis du patron ${ }^{24}$. Elles régissent d'abord l'ordre chronologique dans lequel interviennent les participants au mağlis. Elles sont parfois acceptées sans discussion par les personnes concernées : nous avons eu l'occasion de constater que, lorsqu'Ašğa' al-Sulamī se présente devant Hārūn al-Rašīd, il doit laisser passer ses aînés en premier (18.212-15). Mais elles sont parfois l'objet d'une rivalité. En effet, lorsqu'il existe une hiérarchie évidente entre les poètes, c'est en fonction de leurs mérites respectifs que l'on organisera l'ordre de passage, ce qui peut être l'occasion de cruelles désillusions pour certains d'entre eux, car la hiérarchie ainsi rendue publique ne correspond pas nécessairement à leurs attentes. Ğarīr (m. 110/728-9) lorsqu'il se rend auprès d'al-Walīd b. 'Abd al-Malik (m. 96/715), l'apprend à ses dépens, comme le raconte Ru'ba (m. 145/762) qui,

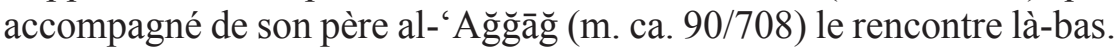

Le premier poète que nous rencontrâmes fut Ğarīr, qui nous fit promettre de ne pas soutenir ceux qui voudraient lui nuire. Le premier poète admis à entrer fut mon père, puis vint mon tour (...).

Plus tard, Ğarīr nous rencontra et nous lança : «Fils de la mère d'al-'Ağğăğg, si je décide de vous écraser, vos pièces de poésie ne vous serviront à rien. »

« Non, par Dieu, pensâmes-nous, personne n'a pu lui rapporter à notre sujet [quelque chose qui l'aurait fâché]. Simplement, il est jaloux de nous, car nous avons été introduits et écoutés avant lui (20.350-4). »

Ainsi, l'ordre de comparution est de nature à provoquer de graves tensions entre les concurrents ${ }^{25}$.

${ }^{24}$ Le Kitāb al-Tāğg rédigé semble-t-il à une époque légèrement plus tardive que celle qui nous intéresse, mentionne de nombreuses règles de ce genre. Ainsi, le souverain doitil s'asseoir en premier, puis la première classe de courtisans, puis la seconde, etc. Au sein de chaque classe, ce sont les personnages de rang le plus élevé qui s'assoient les premiers ([Pseudo-] al-Ğāḥiz, Al-Tāğ fì ah̆lāq al-mulūk, p. 50). De la même manière, sauf permission spéciale, seuls les nobles peuvent d'approcher du souverain (p. 49).

${ }^{25}$ Le même genre de préoccupation occupe les courtisans attachés durablement à un patron, qui, eux, se disputeront non plus sur l'ordre de passage mais sur les modalités d'accès au patron. Nous disposons d'un exemple avec des chanteurs : Ishāa al-Mawșilī disposait d'une nawba, c'est-à-dire d'une date et d'un horaire réguliers auxquels il était admis auprès du calife al-Rašīì. Son rival, le chanteur Ibrāhīm b. Ahī Salama obtient du calife que sa nawba soit en même temps que celle d'Isḥāq. Non content d'obtenir cet honneur, Ibrāhīm b. Ah̄̄ Salama se rend le jour de la nawba commune chez Isḥāq, frappe brutalement à sa porte, refuse d'entrer, ce qui contraint ainsi Isḥāq à sortir à sa rencontre - autre exemple d'inscription d'un rapport de force dans l'espace - et l'informe que désormais, pour comparaître devant le calife, il devra attendre qu'Ibn Ahī Salama lui envoie un messager ; il devra ensuite se rendre à son domicile, puis partir de là avec lui au palais 
Néanmoins, plutôt que de parler en premier, un poète peut préférer retarder son intervention et avoir le dernier mot.

Lorsqu'al-Wātiq [m. 232/847] devint calife, il siégea publiquement. On vint le féliciter ; les poètes le louèrent. Puis Ḥusayn b. al-Ḍaḥhāa demanda la permission de réciter, une fois qu'ils eurent fini — il était au nombre des commensaux [du nouveau calife] et estimait donc que réciter avec les poètes aurait été indigne de lui. [Le calife] la lui accorda, et il lui récita le poème dans lequel il dit :

Je cache en vain mon amour pour quelqu'un qui, si je me plaignais à lui, me prendrait en pitié (7.194-14).

En attendant que le commun des poètes ait récité, Ibn al-Ḍaḥhāk marque l'incommensurable distance qui sépare l'insider, convaincu de sa valeur et fort de la certitude de sa position, des outsiders, contraints de réciter dans les conditions que nous décrivions plus haut, dans l'espoir de se distinguer. Ašğa' al-Sulamī procède de la même façon lorsque Ğa'far b. Yahyā reçoit les félicitations des poètes pour sa nomination comme gouverneur du Hurāsān, mais les raisons de son attitude ne sont pas exprimées (18.224-10). Ces règles de préséance constituent donc le cadre dans lequel doivent se couler les prétentions des poètes ; mais la généralité de ces règles offre une marge de négociation qui implique non seulement le patron, mais également les concurrents.

\section{Bienséances}

Le poète admis au sein de l'espace patronal doit négocier les distances mais aussi tenir sa place, c'est-à-dire respecter les règles de bienséance qui régissent le mağlis où il est introduit. Là encore, les prétentions doivent être soigneusement dosées sans quoi le prétendant risque d'être remis à sa place, voire expulsé de l'espace patronal. Ces prétentions peuvent s'inclure très nettement dans l'espace : Isḥāq al-Mawșilī, encore lui, nous en fournit plusieurs exemples. Fameux pour ses dons de musicien, il se considère avant tout comme un poète ${ }^{26}$

et ne pas entrer sans qu'il soit présent. Abattu, Isḥāq le suit, mais ne manque pas de se plaindre à al-Faḍl b. al-Rabī', qui plaide sa cause auprès du calife. Ce dernier, informé des propos d'Ibrāhīm b. Ahī Salama, rétablit la vérité, et indique qu'Isḥāq peut venir le voir quand il le veut et seul (5.381-9).

${ }^{26}$ Il prétend avoir vu Ğarīr en rêve pour se présenter comme son héritier et est déclaré le meilleur poète de son temps (5.274-17). 
et n'aime guère être associé au chant (5.268-10*). On ne s'étonne donc guère de le voir un jour demander à al-Ma'mūn l'autorisation de ne plus entrer avec les chanteurs, mais avec les savants et les lettrés ( $a h l$ al- 'ilm wa-l-adab wa-l-riwāya) et même avec les théologiens. Il pousse même l'audace à demander un jour l'autorisation de se vêtir de noir ${ }^{27}$ (couleur des Abbassides) le vendredi et de prier dans la même loge (maqșüra) que le calife. Cette dernière demande est rejetée (5.286-3). De la même manière, contrairement aux autres chanteurs, Isḥāq s'assoit parmi les commensaux (nadīm) du calife al-Wātiq. Lorsqu'il doit chanter, il sort légèrement du rang et on lui amène son instrument. Une fois sa performance terminée, il regagne sa place parmi les commensaux (5.295-11). Ce personnage, qui ne tient pas en place parce qu'il ne veut pas être tenu par sa place, est toutefois conscient de certaines limites. Lorsqu'al-Mu'tașim (m. 227/842) l'invite à se rapprocher de lui, le poète-chanteur hésite, car s'il s'exécute, il se trouvera sur le même rang que l'ombrageux chef militaire Isḥāq b. Ibrāhīm al-Muṣ abī (m. 235/850). Il faut que le calife justifie à haute voix l'honneur qui lui est fait pour qu'al-Mawșilī s'exécute (5.401-8).

Dans cette négociation de la proximité, le patron n'est pas passif. Le calife peut choisir d'établir une limite matérielle entre lui et le reste de ses sujets ${ }^{28}$, si proches de lui soient-ils. Ainsi, certains califes, comme al-Muqtadir (m. 320/932), écoutaient la musique cachés derrière un rideau ${ }^{29}$, en compagnie de leurs concubines (5.221-14).

${ }^{27}$ Hilāl al-Ṣābi' (m. 448/1056) indique - à une époque donc plus tardive — que la couleur noire, dans les cérémonies, est réservée à une petit groupe de haut dignitaires : les Abbassides, certains juges, les chefs militaires et les émirs (Rusūm dār al-ḩilāfa, pp. 91-92).

${ }^{28}$ Au-delà des choix individuels des califes, le protocole va dans le sens d'un durcissement comme le notent déjà les sources anciennes (Șābi', Rusūm dār al-hilāâ, p. 31), qui éloigne le commandeur des croyants à la fois spatialement mais aussi symboliquement de ses sujets.

${ }^{29}$ Le $K$. al-Tăğ retrace l'utilisation du rideau pour séparer le souverain de ses commensaux, de l'époque sassanide jusqu'à celle d'al-Ma'mūn ([Pseudo-] al-Ğāḥiz [= Muhammad b. al-Ḥārit al-Ta 'labī (m. 250/864)], al-Tāğ fì ahlāq al-mulük, pp. 26-43). L'abandon du rideau est associé, pour les Omeyyades, à la corruption du pouvoir politique (pp. 2931), illustrant l'idée, récurrente dans l'ouvrage, selon laquelle le respect par le souverain des règles du cérémonial reflète sa rectitude dans ses rapports avec ses sujets (p. 44, 47 et passim). On note que, dans ce passage, les anecdotes mettant en scène al-Rašĩ̄d et des chanteurs insistent sur la présence d'un rideau derrière lequel se trouve le calife (par ex. p. 38 et 39), alors que cet élément n'est guère mis en avant dans le Livre des chansons. 
D'autres, comme al-Hādī, se montrent au contraire à leurs commensaux (5.184-3). Les califes peuvent par ailleurs choisir d'honorer leurs courtisans en leur accordant une proximité spéciale : lorsqu'Isḥāq alMawșilī se présente à al-Mutawakkil (m. 247/861), le fait asseoir en face de lui, à la même hauteur ${ }^{30}$ (rafa 'ahu hattā ağlasahu quddāma lsarīr) (5.414-10).

À d'autres moments, les prétentions mal ajustées des poètes constituent des erreurs de placement sanctionnées par une expulsion pure et simple de l'espace patronal. Un exemple d'erreurs cumulées nous est donné dans une anecdote figurant dans la notice de Manșūr al-Namarī.

Hārūn, le commandeur des croyants, acceptait qu'on lui prête des qualités propres aux prophètes dans les panégyriques. Il ne désapprouvait ni ne récusait de tels propos. Cependant, un groupe de poètes se présenta à lui, au sein duquel se trouvait un descendant de Zuhayr b. Abī Sulmā [m. 609]. Celui-ci se montra excessif dans son éloge au point de dire :

On dirait que c'est un nouveau prophète après le Prophète

Hārūn se courrouça et personne ne put tirer profit [de sa générosité] ce jour-là. Il priva ce poète de récompense, refusant de lui accorder quoi que ce soit. Manșūr al-Namarī récita un poème dans lequel il faisait son éloge et satirisait et dénigrait les Alides. Excédé, Hārūn lui lança :

- Fils de gueuse ! penses-tu gagner ma faveur en satirisant des gens qui ont le même ancêtre, la même parenté, et le même lignage que moi ?

— Je ne parle que de ce que je connais, répondit-il.

La colère du calife s'accrut encore, et il ordonna à Masrūr de lui frapper la nuque et de le mettre dehors (13.143-16).

Le vers du maladroit descendant de Zuhayr confine au blasphème, puisque pour tout musulman, Muhammad est le " sceau des prophètes ». Le commandeur des croyants ne peut que manifester sa colère en privant l'importun de récompense, mesure assez exceptionnelle ${ }^{31}$. Le poète, dont le nom n'est pas donné, a mal anticipé les attentes du calife et a produit un énoncé déplacé. Ce faisant, il va

${ }^{30}$ Il lui offre également un coussin comme l'avait fait al-Mu'tașim la première fois qu'Ishāa était venu le voir après son avènement. Cette gratification symbolique est une manière de réaffirmer publiquement le lien ancien qui unit les Abbassides et Ishạāq. Pour d'autres exemples (mais n'impliquant pas de poètes) de négociation des bienséances, voir Hamori, "Rising to Greet You: Some Comedies of Manners", pp. 205-210.

${ }^{31}$ Voir notre analyse du récit de la rencontre la visite de Muṭī b. Iyās à Ğarīr b. Yazīd (13.303-1) dans notre article "Rhétorique du don", p. 107. 
créer un climat de suspicion à propos de la parole des autres poètes qui l'accompagnent, ce dont Manșūr al-Namar̄̄ va faire les frais. Introduit en même temps que son maladroit confrère, il récite après lui. Comme lui, il essaie d'anticiper les attentes de son protecteur et mise sur son goût pour les diatribes anti-alides. C'est d'ailleurs à l'aide d'un tel positionnement qu'il avait gagné la faveur du calife (13.140-18*). Or la satire des descendants du Prophète, qui aurait pu être acceptée dans un autre contexte, ne saurait l'être après le vers blasphématoire qui a précédé. C'est pour cette raison que le calife se solidarise avec les Alides en soulignant sa parenté avec eux et fait frapper et jeter hors du palais le malheureux Manșūr. Ces deux poètes n'ont pas fait preuve de sens du placement et se dont donc exposés à des sanctions rares dans notre corpus : la privation de récompense et l'expulsion.

Dans ce cadre également, le respect des bienséances n'est pas nécessairement imposé par le maître des lieux. L'assistance exerce une pression permanente et parfois plus sourcilleuse que celle du patron, comme l'apprend Isḥāq al-Mawșilī auprès d'al-Mu'tașim : le calife récite un vers de façon inexacte ; le poète-chanteur relève l'erreur sans grand ménagement, mais se rend compte de son impair lorsque le calife lui fait un clin d'œil pour le mettre en garde contre la réaction d'Isḥāq al-Muṣ ${ }^{\prime} a b i ̄$ (m. 235/850), qui avait l'habitude de châtier sévèrement quiconque se laisser aller à de telles privautés à l'endroit du calife. La réaction d'al-Mu'tașim suggère que, si al-Muș'abī avait châtié Isḥāq, il aurait été difficile de lui donner tort ${ }^{32}$. Il existe donc bien une surveillance collective du comportement des courtisans dans l'entourage du maître des lieux (5.401-8).

\section{Prendre congé}

Quel que soit l'état de la relation, le départ d'un des deux protagonistes met à l'épreuve la solidité des liens personnels; d'abord, parce qu'il rompt le contact et l'immédiateté des interactions; ensuite,

\footnotetext{
${ }^{32}$ L'ouvrage de Hilāl al-Șābi' donne effectivement tort à al-Mawșilī : si le calife commet une erreur linguistique, mentionne un hadị tapocryphe ou récite une poésie de façon inexacte, on ne doit jamais le corriger, mais, tout au plus, essayer d'attirer son attention sur l'erreur par de discrètes allusions (Rusūm dār al-ḩilāfa, p. 52).
} 
parce que les parties, si elles ne souhaitent pas que cette séparation soit interprétée comme une rupture, doivent là encore respecter certaines formes, qui sont autant d'occasions pour les protagonistes de montrer à leur partenaire et aux tiers comment ils envisagent leur relation.

Nous l'avons vu, les départs en voyage d'un patron sont fréquemment l'occasion d'audiences publiques où les visiteurs peuvent venir solliciter telle ou telle faveur avant le départ du maître des lieux. De son côté, le poète, lorsqu'il se trouve dans une relation exclusive avec son patron et est soumis à une obligation de disponibilité permanente, se voit parfois contraint de justifier ses absences. À l'occasion, son protecteur pourra le forcer à remplir ses devoirs. Les personnages très fortement intégrés à l'entourage patronal doivent demander des autorisations d'absence exceptionnelles. Lorsqu' Isḥāq al-Mawșilī souhaite s'absenter, le calife lui accorde le samedi, car il n'aime pas ce jour (5.231-11). D'une façon générale, on s'attend à ce qu'un habitué d'une maison justifie ses absences. Les questions de Gaa'far b. Yahyāa à Ibrāhīm al-Mawșilī sur son fills qui ne rend plus visite au vizir (5.327-8) en sont une marque discrète et courtoise.

Les justifications apportées aux absences ne sont pas toujours très convaincantes et leur faiblesse est parfois compensée par des vers et des chants. Ainsi, quand Isḥāq al-Mawșilī disparaît plusieurs jours de Raqqa, il calme la colère d'al-Rašīd qui l'a cherché en vain en chantant des vers dans lesquels il décrit la beauté de la jeune chrétienne qui l'a servi puis en racontant son aventure (5.373-1). Le poème, le chant et le récit fonctionnent ici comme une sorte de ransom tale. Si le poète persiste à s'absenter, le patron peut choisir de le contraindre à rester à ses côtés, comme le fait un calife (al-Saffāḥ [m. 136/754] ou alManșūr) avec Abū Dulāma (m. 161/778 ou 170/786). Ce dernier s'absentant fréquemment pour courir les tavernes, son protecteur décide de lui imposer d'accomplir toutes ses prières au palais califal. Le poète ne supportant pas ce traitement, il parvient à ses fins à l'aide de quelques vers dans lesquels il se plaint de cette piété forcée (10.347-15). Le texte précise bien que la chose qui déplaît au calife est l'absence du poète et non le fait qu'il s'adonne à la boisson : «il lui reprocha d'avoir interrompu ses relations avec lui » (fa- 'àtabahu 'alā nqițā 'ihi 'anhu).

La poésie joue donc un rôle important dans la légitimation des déplacements. Bien plus, on pourrait même dire qu'elle en est souvent le préalable indispensable. En effet, le poète, lié à son bienfaiteur par 
la $n i$ ' $m a$, doit justifier son départ de manière à ce que cette séparation ne puisse pas être interprétée comme un acte d'insatisfaction. Il s'agit, pour le poète, d'empêcher que le patron n'y voie un acte de défiance et, pour le patron, d'empêcher que les tiers n'y flairent une dénonciation de son avarice. Ce souci explique d'ailleurs la mise en scène à laquelle se livre Harb b. Ḩālid b. Yazīd b. Mu'āwiya : lorsqu'un visiteur arrive dans la cour de sa maison, ses serviteurs se précipitent pour l'aider à décharger ses bagages et s'occuper de sa monture. En revanche, lorsque le visiteur repart, il ne peut compter sur leur aide. Soumis à ce traitement, le poète Dāwūd b. Salm (m. 132/750) craint d'avoir froissé son hôte mais les serviteurs expliquent : « Nous aidons ceux qui nous rendent visite, pas ceux qui nous quittent. » Un témoin, qui entend le poète relater cette histoire, déclare cette réponse plus flatteuse que son panégyrique (6.19-1). Le départ, parce qu'il met à l'épreuve le lien qui unit le poète et son bienfaiteur doit donc faire l'objet d'une attention particulière.

Dans l'anecdote que nous venons de mentionner, la demande de congé présentée par le poète est rendue par le verbe ista'dana - le même employé d'ailleurs pour demander la permission d'entrer — sans précision sur la forme ou la publicité de la demande. Il est toutefois attesté que la qașìda sert parfois à exprimer une telle requête. Un récit mettant en scène Ibn Harma (m. 176/792) et al-Sarī b. 'Abd Allāh chez qui il avait résidé un temps nous montre les formes très codifiées dans lesquelles peut s'exprimer la demande de congé. C'est le patron qui parle :

Puis il demeura quelques jours, puis il me dit : « Je me languis. » « Dis des vers dans lesquels tu te languis, lui répondis-je $\left(4.386-7^{*}\right)$. »

Le poète récite ensuite un poème dans lequel il évoque dans un premier temps des lieux dont il est nostalgique avant de faire l'éloge d'al-Sarī. Le poète repart ensuite avec une récompense augmentée de très larges défraiements pour son voyage et pour l'achat de cadeaux à sa famille. Le mécanisme repose donc sur une euphémisation : le départ est justifié par le $\check{s} a w q$, ce sentiment de manque qui saisit ceux qui sont séparés d'un lieu ou d'un être aimé, c'est-à-dire par un état psychologique qui échappe théoriquement à la volonté du poète et au pouvoir du patron. En outre, ce sentiment est exprimé en des vers qui permettent non seulement l'exhibition de ce sentiment qui disculpe les 
deux parties de la rupture, mais qui seront l'occasion de faire une dernière fois l'éloge du patron et d'affirmer la permanence du lien. La chose apparaît nettement dans deux des vers cités (nous soulignons) :

C'est lui qui - après Dieu - m'a sauvé et je ne l'oublierai pas, ni la manière dont il m'a sauvé et sorti d'affaire.

Je t'offrirai des éloges de choix qui accompagneront les pèlerins à toute période de l'année.

Ce procédé est employé par l'un des derniers poètes qui ne réside pas à temps complet en ville, espèce rare dans notre corpus. Toutefois, le procédé employé par Ibn Harma et al-Sarī b. 'Abd Allāh est très bien attesté parmi les poètes citadins.

En effet, les poètes sont souvent tenus d'accompagner leur protecteur lorsqu'il part en voyage. Ces déplacements forcés sont plus ou moins bien supportés et les demandes de congés se multiplient, prenant fréquemment la forme de la poésie du " mal du pays » (alhanīn ilā l-awtạn $\left.n^{33}\right)$. Le procédé est plusieurs fois employé par Isḥāq al-Mawșilīin ${ }^{34}$, sans être toujours compris car certains ne saisissent pas la demande euphémisée que contiennent ces vers :

Ḥammād b. Isḥāq nous a rapporté cette histoire qu'il tenait de son père : « Je chantai un jour à al-Wātiq des vers de ma composition, alors que je me trouvais près de lui à Samarra, depuis un long moment, et que les miens me manquaient. Cet air disait :

Comme j'aime le vent du sud quand il se fait sentir au matin, soufflant doucement, Chargé de la fraîcheur de la rosée, porteur d'une senteur de ğatğāt et de basbās ${ }^{35}$. Il but en l'écoutant et l'apprécia.

— Abū Muhammad, me dit-il, si tu avais dit au lieu de « Comme j' aime le vent du sud » «Comme j'aime le vent du nord », n'aurait-ce pas été plus délicat, plus agréable, plus sain, moins lourd, plus doux enfin pour l'esprit?

${ }^{33} \mathrm{Ce}$ thème connaît une faveur toute particulière à l'époque abbasside. On se rappellera qu'Abū l-Farağ al-Ișbahānī lui-même est l'auteur présumé d'un ouvrage portant sur le même thème : Adab al-giurabā', p. 118 [Voir au sujet de ce livre la traduction et le commentaire de Crone et Moreh sous le titre de The Book of Strangers et l'étude de Georgine Ayoub sur le même ouvrage "Les traces de l'étranger", pp. 79-106]. Al-Șūlī inclut d'ailleurs dans la liste des sujets dans lesquels les Modernes ont surpassé les Anciens le hanīn ilā l-awțān (Ahbūr Abī Tammām, p. 22-24), comme le relève Gruendler, "Verse and Taxes: The Function of Poetry in Selected Literary Akhbār of the Third/Ninth Century", p. 101). Pour une étude historique de ce motif depuis l'antéislam, voir Arazi, "Al-Hanīn ilā al-awțān, entre la Ğāhiliyya et l'Islam — Le Bédouin et le citadin réconciliés".

${ }^{34}$ Par exemple : $5.355-13$; 5.357-6* ; 5.363-2* ; 5.406-8 ; 5.415-10.

${ }^{35}$ Plantes odoriférantes. 
- Ce que remarque le commandeur des croyants ne m'a pas échappé, mais l'explication vient dans la suite.

- Je t'écoute.

- Quelle passion et quelle nostalgie réveillera-t-il chez l'amant, après la stupeur et le désespoir? poursuivis-je.

- Ce que tu trouves agréable, c'est le doux souvenir des gens de Bagdad que t'apporte le vent du sud, et non ce vent en lui-même. Ce sont eux qui te manquent, pas lui.

- C'est vrai, commandeur des croyants, lui dis-je, en me levant pour lui baiser la main.

Il sourit et dit :

- Je t'autorise à partir dans trois jours. Fais bonne route.

Il me fit donner 1000 dirhams (5.406-8). »

D'autres poètes, tels al-'Abbās b. al-Aḥnaf (m. entre 188/804 et $193 / 809$ ), ont recours à ce procédé (dans une formulation toutefois beaucoup moins ambiguë) (8.372-5) et même la propre sœur d'alRašīd, 'Ulayya bt. al-Mahdī (m. 210/825), compose et chante une poésie sur le thème de l'exil pour obtenir l'autorisation de revenir vers l'Iraq lors d'un voyage à Rayy (10.182-16). Ces quelques exemples nous montrent que ce thème poétique joue un rôle non négligeable dans la légitimation des déplacements des poètes ${ }^{36}$.

Toutefois, tous les poètes n'accompagnent pas leur patron lorsqu'il part en voyage. Les poèmes d'adieu peuvent jouer un rôle analogue aux demandes de congé que nous venons de passer en revue : ils servent alors à réaffirmer le lien non seulement aux yeux du partenaire, mais aussi aux yeux des tiers. Ainsi, quand al-Faḍl b. Yaḥyā part pour le Hurāsān, Isḥāq al-Mawșilī lui déclame des vers d'adieu. Le vizir lui demande de les mettre en musique et de les enseigner à l'un des chanteurs qui part avec lui. Après son départ, il envoie à Isḥāq à chaque fois qu'il écoute le chant 1000 dinars, un montant équivalent à celui qu'il lui avait accordé après la première récitation (5.301-16). Ce faisant, il montre au poète que la distance n'annule pas leurs liens, et manifeste aux yeux d'autrui sa fidélité et sa libéralité.

${ }^{36}$ Même si ce n'est pas son unique fonction : ainsi, quand lors d'un voyage du calife al-Mu'tașim vers la Syrie pour guerroyer contre les Byzantins, il demande Husayn b. alḌaḥhāk des vers sur ce même thème, afin que 'Amr b. Bāna les lui chante (7.192-15). 


\section{Conclusion}

L'ensemble des observations exposées ci-dessus prouve à l'envi que les placements et les déplacements des poètes sont hautement réglés et que le passage d'un espace à un autre ne se fait jamais sans que le prétendant ne soumette son comportement et sa poésie à des filtres qui garantissent que les mauvaises personnes ne se retrouveront pas au mauvais endroit. De la même manière qu'aujourd'hui, le pouvoir politique ne confie jamais la rédaction d'un rapport à des experts dont il ne puisse prévoir au moins grossièrement les conclusions, on ne laisse pas un poète prendre la parole au VIIIe siècle sans s'être assuré qu'il connaît les règles du jeu et ne réserve pas de mauvaise surprise.

On manquerait toutefois une dimension importante de cette rhétorique de la distance en en faisant le produit d'une étiquette immuable et absolument extérieure aux acteurs. Bien au contraire, il s'agit, à chacune des étapes de la relation, d'un processus dynamique où se (re)négocient les termes de la relation patronale. De plus, loin d'enfermer les parties dans un tête-à-tête, ces mécanismes reposent tantôt sur la mise en compétition des poètes (et plus généralement des courtisans), tantôt sur des intercessions et des échanges de bons procédés entre insiders et outsiders. Enfin, si le patron dispose d'une marge de manœuvre plus importante dans l'application de ces règles, il ne peut jamais s'en affranchir discrétionnairement, car leur respect est généralement assuré par l'ensemble de son entourage.

Ces observations se vérifieraient sans doute, mutatis mutandis, pour l'ensemble des catégories sociales pour lesquelles le contact avec le patron est essentiel (chanteurs, commensaux, etc.). Il existe toutefois une spécificité évidente, qui distingue nettement les poètes des autres groupes : la poésie elle-même, qui non seulement décrit mais aussi agit $^{37}$. Comme nous l'avons vu, ce sont bien souvent des vers qui permettent le passage harmonieux d'un espace à un autre. À ce titre, il n'est pas abusif de dire que la poésie contribue à façonner la relation.

${ }^{37}$ Cette distinction, assez nette dans les premières décennies du califat abbasside, l'est beaucoup moins par la suite, à mesure que la frontière entre poètes professionnels et commensaux s'estompe. On constate ainsi des phénomènes très voisins de ceux décrits ici dans la carrière d'al-Șūlī, nadīm, secrétaire, et précepteur. Voir l'article de Osti, "The Remuneration of a Court Companion in Theory and Practice: A Case Study", pp. 85-107. 
Mais elle est à son tour influencée (et parfois même générée) par les exigences de cette proxémique patronale.

Tous ces éléments assurent dans l'ensemble un fonctionnement prévisible et donc largement apaisé de l'institution patronale, où les places sont suffisamment définies pour préserver les principales composantes de l'ordre social, mais de manière suffisamment vague pour donner à chacun la possibilité d'améliorer son lot au moyen de négociations et de mises en concurrence sans cesse renouvelées.

Mais, ce disant, ne minimisons-nous pas les risques de la carrière poétique ? Est-ce un pur hasard si Muhammad b. Habīb (m. 245/860) consacre la moitié (en fait un ouvrage indépendant à l'origine) de son

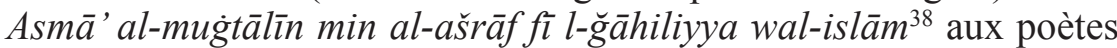
morts assassinés ? Force est de constater que notre corpus, qui s'étale sur quelques décennies seulement, fait état de plusieurs morts violentes : Ibn al-Dumayna (m. 143/760 ou après) meurt dans un règlement de compte tribal (17.93-9*), Di‘bil b. 'Alī (m. ca. 244/859) est tué d'un coup de canne empoisonnée dans un village du Sūs (20.186-4*), Abū Nuhayla (m. ca. 147/764) est égorgé sur la route du Hurāsān (20.39014*), Manșūr al-Namarī meurt avant que les hommes du calife ne se saisissent de lui (13.148-3); de la même façon, Ḥammād 'Ağrad meurt pendant sa fuite devant Muḥammad b. Sulaymān b. 'Alī (m. 173/789) à Širzad̄ān (14.380-5), Baššār b. Burd est pris à Bașra alors qu'il vient d'appeler à la prière en état d'ivresse (3.244-2). Il ne s'agit donc pas d'affirmer que la stabilité croissante des relations de patronage à cette époque protège les poètes d'une fin violente. Mais, puisque cet article porte sur les espaces, force est de constater que ces assassinats ont toujours lieu hors d'une demeure patronale. Ce phénomène ne devrait pas être perdu de vue : à aucun moment, dans notre corpus, un poète n'est exécuté devant le destinataire d'un poème. Aussi, assimiler la situation du poète devant un prince à une relation de résistance au pouvoir de l'épée ou à la force brute reflète sans doute plus un discours de dramatisation au service des acteurs que la réalité des faits.

\footnotetext{
${ }^{38}$ Ibn Ḥabīb, “Asmā’ al-mug̣tālīn min al-ašrāf fĩ l-ğāhiliyya wa-l-islām”, II, p. 105278.
} 


\section{Bibliographie}

Arazi, Albert, “Al-Ḥan̄̄n ilā al-awțān, entre la Ğāhiliyya et l'Islam — Le Bédouin et le citadin réconciliés", Zeitschrift der Deutschen Morgenländischen Gesellschaft, 143, 2 (1993), pp. 287-327.

Ayoub, Georgine, "Les traces de l'étranger", in Brigitte Foulon (éd.), L'écriture de la nostalgie dans la littérature arabe : actes du colloque de l'INALCO des 30 et 31 mars 2010, Paris, L'Harmattan, 2013, pp. 79-106.

Bencheikh, Jamel-Eddine, "Les musiciens et la poésie. Les écoles d'Isḥāq alMawșilī (m. 225 H.) et d'Ibrāhīm Ibn al-Mahdī (m. 224 H.)", Arabica, 22/2 (1975), pp. 114-152.

Bray, Julia, "Third and Fourth Century Bleeding Poetry", Arabic and Middle Eastern Literatures, 2, 1 (1999), pp. 75-92.

Certeau, Michel de, L'invention du quotidien. 1/ Arts de faire, Paris, Gallimard, 1990.

Cooperson, Michael, "Probability, Plausibility and « Spiritual Communion » in Classical Arabic Biography", en Philip F. Kennedy (éd.), On Fiction and Adab in Medieval Arabic Literature, Wiesbaden, Harrassowitz, 2005, pp. 69-83.

El-Cheikh, Nadia Maria, "Servants at the Gate: Eunuchs at the Court of AlMuqtadir", Journal of the Economic and Social History of the Orient, 48, 2 (2005), pp. 234-252.

El-Cheikh, Nadia Maria, "The Institutionalisation of Abbāsid Ceremonial", en Ana Rodríguez López et John Hudson (éds.), Diverging Paths? The Shapes of Power and Institutions in Medieval Christendom and Islam, Leyde-Boston, Brill, 2014, pp. 351-370.

El-Cheikh, Nadia Maria, "The Qahramâna in the Abbasid Court: Position and Functions", Studia Islamica, 97 (2003), pp. 41-55.

[Pseudo-] al-Ğāḥiz [Muhammad b. al-Hâarit al-Ta'labī (m. 250/864)], Al-Tāğ fì ahlāq al-mulūk, Le Caire, Imprimerie nationale, 1914.

Gruendler, Beatrice, "Verse and Taxes: The Function of Poetry in Selected Literary Akhbār of the Third/Ninth Century", en Philip F. Kennedy (éd.), On Fiction and Adab in Medieval Arabic Literature, Wiesbaden, Harrassowitz, 2005, pp. 85-124.

Gruendler, Beatrice, "Meeting the Patron: an Akhbār Type and Its Implications for Muhdath Poetry”, en Sebastian Günther (éd.), Ideas, Images, Methods of Portrayal: Insights into Classical Arabic Literature and Islam, LeidenBoston, Brill, 2005, pp. 59-88.

Gruendler, Beatrice, "Qașīda: Its Reconstruction in Performance", Beatrice Gruendler (ed.), Classical Arabic Humanities in Their Own Terms. Festschrift for Wolfhart Heinrichs on His 65th Birthday, Leiden-Boston, Brill, 2008, pp. 325-389. 
Hamori, Andras, "Rising to Greet You: Some Comedies of Manners", Middle Eastern Literatures, 11, 2 (2008), pp. 205-210.

Hoorelbeke, Mathias, "Rhétorique du don: patronage, performance poétique et rétribution dans les premières décennies du califat abbasside", Arabica, 62, 1 (2015), pp. 99-127.

Ibn Ḥabīb, Muḥammad, “Asmā' al-muggtālīn min al-ašrāf fĩ l-ğāhiliyya walislām”, en 'Abd al-Salām Muḥammad Hārūn (éd.), Nawādir al-Maḥtūṭ̂at, 2 éd., Le Caire, Šarikat wa-maṭba'at al-Bābī al-Halabī bi-Mișr, 1973, II, p. 105-278.

Ișbahānī (al-), Abū al-Farağ 'Alī b. al-Husayn, The Book of Strangers: Mediaeval Arabic Graffiti on the Theme of Nostalgia, traduit par Shmuel Moreh et Patricia Crone, Princeton, M. Wiener, 2000.

Iṣbahānī (al-), Abū al-Farağ 'Alī b. al-Ḥusayn, Kitāb al-Ag்ānī, Le Caire, Dār alkutub, 1927-1961 (vol. I-XVI) et al-Hay’a al-mișriyya al-‘āmma li-l-ta'līf wa-l-našr, 1970-1974 (vol. XVII-XXIV).

Iṣbahān̄̄ (al-), Abū al-Farağ 'Alī b. al-Ḥusayn, Adab al-giurabā', Beyrouth, Dār al-kitāb al-ğadīd, 1972.

Kilpatrick, Hilary, Making the Great Book of Songs: Compilation and the Author's Craft in Abu l-Faraj al-Ișbahānī's Kitāb al-aghānī, Londres, RoutledgeCurzon, 2003.

Marsham, Andrew, Rituals of Islamic Monarchy: Accession and Succession in the First Muslim Empire, Edimbourg, Edinburgh University Press, 2009.

Marzubānī (al-), Abū 'Abd Allāh Muḥammad b. 'Imrān, Al-Muwaššah fì ma'āhnid al- 'ulamā' 'alā l-šsu 'arā', Beyrouth, Dār al-kutub al-'ilmiyya, 1995.

Meyer, Michel, Principia rhetorica : Théorie générale de l'argumentation, Paris, Fayard, 2008.

Osti, Letizia, "Ibn Bassām: A Case Study on Poetry and Power", Middle Eastern Literatures, 10, 1 (2007), pp. 1-14.

Osti, Letizia, "The Remuneration of a Court Companion in Theory and Practice: A Case Study", Journal of Abbassid Studies, 1 (2014), pp. 85-107.

Șābi' (al-) Hilāl, Rusūm dār al-hilāfa, 2e éd., Beyrouth, Dār al-rā'id al-'arabī, 1986.

Sharlet, Jocelyn, "Tokens of Resentment: Medieval Arabic Narratives about Gift Exchange and Social Conflict", Journal of Arabic and Islamic Studies, 11, 3 (2011), pp. 62-100.

Sharlet, Jocelyn, Patronage and Poetry in the Islamic World: Social Mobility and Status in the Medieval Middle East and Central Asia, Londres-New York, I. B. Tauris, 2011.

Stetkevych, Suzanne Pinckney, The Poetics of Islamic Legitimacy: Myth, Gender, and Ceremony in the Classical Arabic Ode, Bloomington, Indiana University Press, 2002. 
Șūlī (al-), Abū Bakr Muḥammad b. Yaḥyā, Ahboār Abī Tammām, Beyrouth, alMaktab al-Tiğārī li-1-țibā'a wa-l-tawzī' wa-al-našr, s.d.

Tillier, Mathieu, "Un espace judiciaire entre public et privé. Audiences de cadis à l'époque 'abbāside", Annales islamologiques, 38 (2004), pp. 491-512.

Recibido: $19 / 03 / 2014$

Aceptado: 17/04/2015 